\title{
Flavor- vs. tone-cued shock avoidance
}

\author{
HOWARD B. PARKER and RICHARD F. SMITH \\ University of Utah, Salt Lake City, Utah 84112
}

\begin{abstract}
In a direct comparison, flavor-cued rats learned to avoid shock in a two-way shuttlebox as well as, or better than, tone-cued rats. These results stand in contrast to the prevalent view that rats encounter difficulty in forming flavor-shock, but not tone-shock, associations. In attempting to account for this contrast, we note that experiments revealing cue-modality specificity employ an aversion paradigm and record ingestive behavior. It is argued that both the paradigm and the dependent variable are inappropriate for assessing shock-avoidance learning, and that cue-modality specificity in such a setting reflects paradigm and response choice rather than a general characteristic of rats.
\end{abstract}

In 1966, Garcia and Koelling made a statement which fostered the cue-modality specificity position and contributed to a subsequent reevaluation of traditional learning theory (e.g., Garcia, McGowan, \& Green, 1972; Rozin \& Kalat, 1971; Seligman, 1970). Part of that statement read: "The avoidance reactions produced by electric shock to the paws transferred to the audiovisual stimulus but not to the gustatory stimulus" (p. 124). (Since olfactory controls were absent, we now recognize that the term "flavor" should have replaced "gustatory" in this quotation. See Garcia, Hankins, \& Coil, 1977, Hankins, Rusiniak, \& Garcia, 1976, and Miller \& Ericson, 1966).

The doctrine of cue-modality specificity was a revolutionary idea in 1966, but in the years since then it has become so firmly established that it can now be accurately described as a dogma of contemporary learning theory.

Oddly, the evidence offered in support of cuemodality specificity in shock-avoidance learning derives not from avoidance paradigms, but from aversion procedures, and the "avoidance" behavior measured (ingestion) bears little relevance to the problem of trauma avoidance (Domjan \& Wilson, 1972; Garcia, Ervin, \& Koelling, 1966; Garcia \& Koelling, 1966; Green, Bouzas, \& Rachlin, 1972; Green, Holmstrom, \& Wollman, 1947; Krane \& Wagner, 1975).

Employing a taste-aversion procedure and measuring ingestion seems, for two reasons, a curious way to evaluate an animal's ability to avoid trauma. First, the use of an aversion-learning procedure in which shock replaces illness is unlikely to reveal evidence of avoidance learning because the procedure does not permit avoidance to occur. Such a pro-

Supported by a grant from the University of Utah Research Committee. The authors wish to thank George Mooney and Patricia Peebles for running subjects. Reprint requests should be addressed to Richard F. Smith, Department of Psychology, University of Utah, Salt Lake City, Utah 84112. cedure may be regarded as lick-contingent classical conditioning. That is, licking is the occasion for the pairing of an audiovisual cue or flavor cue with unavoidable shock. While additional "trials" (in the classical conditioning sense) may be avoided if the animal refrains from further drinking, this curious procedure hardly resembles an avoidance paradigm, in which the performance of a specific behavior during or shortly after a warning signal permits the animal to avoid shock.

Second, even if the aversion procedure should somehow provide the subject with avoidance training, it seems unlikely that the suppression of ingestion would be the response learned. Animals avoid poisoning by refusing to eat poisonous substances (suppressed ingestion). Animals avoid peripheral trauma in several ways (threat, freezing, flight, etc.). The converse is rarely the case. Suppressed ingestion may sometimes be an indirect consequence of typical trauma-avoidance responses, but it does not by itself constitute such a response. When one fails to drink from a mug of very hot coffee, for example, the response is more accurately described as contact avoidance than as suppressed ingestion. The coffee will be consumed when it cools. Bolles (1970), Breland and Breland (1966), Seligman (1970), and others have recognized that animals favor different response strategies when confronted with different sorts of environmental events. In agreement with their views, we are suggesting that the suppression of ingestion is a poor response choice if one wishes to assess shockavoidance behavior. A locomotor response would be preferable.

In view of these issues, it is our contention that the question of cue-modality specificity in shock-avoidance learning should be evaluated with a procedure that (1) permits the animal to obtain the avoidance cue and still avoid the shock, and (2) permits, and measures, a response appropriate to the avoidance of peripheral trauma. We know of only one study which tested flavor-cued avoidance in such a setting (Hankins 
et al., 1976). Whether flavor-cued avoidance was possible in three additional experiments (Garcia, Hankins, \& Rusiniak, 1974; Garcia, Kovner, \& Green, 1970; Garcia, McGowan, \& Green, 1972) could not be determined from the procedure descriptions contained in these papers.

In addition to making explicit the issues discussed above, the present paper replicates the Hankins et al. (1976) finding and directly compares flavor-cued with tone-cued avoidance.

\section{METHOD}

\section{Subjects}

Fifteen 90-day-old Sprague-Dawley rats obtained from Simonsen Laboratories were divided into three groups matched on the basis of weight, and were housed in standard cages measuring $18 \times 24$ $\times 18 \mathrm{~cm}$. The laboratory was maintained at $21^{\circ} \mathrm{C}$ with a 12 -h-on/ 12-h-off light cycle. Over a period of 2 weeks, two of the three groups were adapted to a 23.5 -h water-deprivation schedule. During this period, one subject from the third group died and was not replaced in the experiment. Food was continuously available except in the test apparatus (two-way shuttlebox). The box measured $20 \times 50 \times 25 \mathrm{~cm}$ and had a $3.5-\mathrm{cm}$-high hurdle separating the two ends. The floor of the box was composed of $1.5-\mathrm{cm}$-diam aluminum tubes connected to a scrambler and shock source. The end walls were drilled to accept drinking spouts monitored by drinkometer circuits.

\section{Procedure}

Each day, all subjects received 1030 -sec trials in the shuttlebox. Shock was presented on half of these trials according to a Gellerman series (Gellerman, 1933). The remaining trials were "safe."

The two groups that were $23.5 \mathrm{~h}$ water deprived were run for 32 consecutive days in the shuttlebox. For these groups, a trial began with the introduction of a drinking spout at one end of the box. On safe trials, the spout was withdrawn $30 \mathrm{sec}$ later and, after a 5-sec intertrial interval, reintroduced at the opposite end of the box to begin the next trial. The same procedure was employed on shock trials, but a .3-mA scrambled ac current was applied to the grid floor at the end containing the spout. Shock was initiated $15 \mathrm{sec}$ after the beginning of such a trial and continued for the remainder of the trial. For these groups, cues correlated with trial type were lick contingent. The lick-contingent flavor group $(n=5)$ encountered tap water on safe trials and a .15 M NaCl solution on shock trials. The lick-contingent tone group encountered tap water on both safe and shock trials, but on shock trials a lick produced a drinkometer-actuated, .5-sec tone $(2,900 \mathrm{~Hz}, 73 \mathrm{~dB})$ delivered through a speaker mounted above the hurdle. Interlick intervals less than $.5 \mathrm{sec}$ (the usual case) resulted in a steady tone that persisted for .5 sec after the last lick. Because cues were lick dependent, cue duration and cue-shock intervals varied and unsignaled shocks were occasionally delivered. For both groups, a correct avoidance response was defined as licking and crossing the hurdle to the safe (nonspout) end within the first $15 \mathrm{sec}$ of a shock trial.

The lick-contingent-tone procedure posed a rather unnatural problem for the animals (auditory cues to peripheral pain do not normally result from licking). It seemed possible, therfore, that we had presented the rats with an information acquisition analog of the response selection problem described in the introduction. In order to evaluate the possibility that tone-cued avoidance was made unusually difficult by the lick contingency, a nondeprived, lick-noncontingent tone group $(n=4)$ was run. The procedure employed was similar to standard tone-cued avoidance procedures, except that, like the lick-contingent groups, the cue-shock relationship was variable. Specifically, the pattern of frequency, latency, and duration of tone cues obtained by the lick-contingent tone subjects was "replayed" for the lick-noncontingent tone group. Procedurally, this was arranged by simply placing a rat in the apparatus and starting a 30-sec "trial clock." If the 30sec trial was safe, no cues or shocks were presented, and the clock was reset after a 5-sec "intertrial" interval. If a shock trial was to occur, then one of the patterns of tone previously obtained by a lick-contingent tone subject was presented. Fifteen seconds after the onset of such a trial, shock was delivered to the end of the shuttlebox where the rat had been at trial onset. As with the other groups, shock continued for $15 \mathrm{sec}$. It was apparent, after 16 blocks of 10 trials, that these animals were performing no better than the lick-contingent tone group, and additional training was discontinued.

\section{RESULTS}

The mean percentage of cued avoidance responses is shown for each of the three groups in Figure 1. Of primary interest is evidence that flavor-cued subjects learned to avoid shock as well as, if not better than, tone-cued subjects. A 2 (groups) $\times 8$ (blocks) ANOVA performed on the avoidance data for the lick-contingent groups revealed a significant blocks effect $[F(7,56)=8.05, p<.01]$, but no reliable group difference or interaction $[F(1,8)=.74, F(7,56)=1.52$, respectively]. A comparison between the first and last blocks of trials revealed a significant increase in percentage of cued avoidance for both the flavor group $[\mathrm{t}(8)=3.46, \mathrm{p}<.01]$ and the lick-contingent tone group $[\mathrm{t}(8)=2.44, \mathrm{p}<.05]$. Thus, both groups improved their ability to avoid shock over trials.

A criterion measure of avoidance was also employed. As can be seen in Table 1, three rats in the flavor group reached a criterion of four cued avoidance responses in any five opportunities in 28, 61, and 62 cued trials. One rat in the lick-contingent tone group reached this criterion and required 72 cued trials to do so.

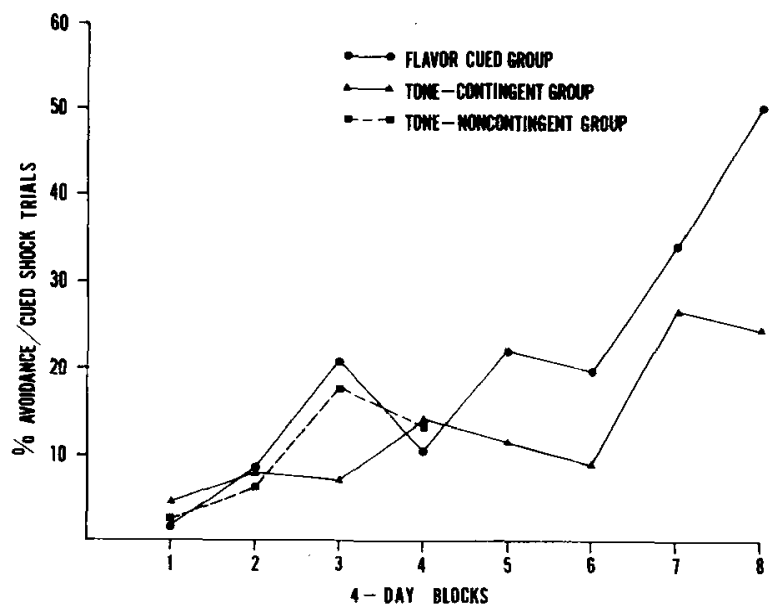

Figure 1. Mean percent of cued shock trials on which avoidance responses occurred. Since animals in the noncontingent tone group failed to learn more rapidly than those in contingent groups, their sessions were discontinued after 160 trials (four blocks). 
Table 1

Individual Subject Performance

\begin{tabular}{crrrrr}
\hline & \multicolumn{5}{c}{ Measure* } \\
\cline { 2 - 5 } Subject & 1 & 2 & 3 & 4 & 5 \\
\hline & & \multicolumn{5}{c}{ Flavor Group } \\
F1 & 61 & 67 & 0 & 6.9 & 9.5 \\
F2 & & 14 & 0 & 7.2 & 12.4 \\
F3 & 28 & 71 & 0 & 5.0 & 14.3 \\
F4 & & 20 & 0 & .7 & 13.2 \\
F5 & 62 & 80 & 0 & 5.1 & 13.3 \\
& & & Tone Group & \\
T1 & & 20 & 0 & 5.2 & 12.3 \\
T2 & & 0 & 0 & 13.0 & 14.1 \\
T3 & 72 & 43 & 8 & 9.0 & 11.6 \\
T4 & & 36 & 0 & 10.0 & 12.8 \\
T5 & & 22 & 22 & 8.8 & 10.1 \\
\hline
\end{tabular}

*Measure 1-Number of cued trials to criterion. Measure 2-Percent cued avoidance on shock trials during the last block. Measure 3-Percent cued "avoidance" on safe trials during the last block. Measure 4-Mean drinking duration on shock trials during last block (seconds). Measure 5-Mean drinking duration on safe trials during last block (seconds).

However, neither of these measures demonstrates that discriminated avoidance was learned in the experiment. If a rat were to leave the drinking chamber after licking for less than $15 \mathrm{sec}$ on both shock and safe trials, it would produce a high shock-avoidance score, but this would not be discriminated avoidance. Such an animal would also produce a high "avoidance" score on safe trials. Table 1 contains the percentage of shock trials avoided and safe trials "avoided" for each animal during the last block of training. One rat ( $\mathrm{T}$ 5) appears to have adopted the strategy of avoiding on every trial. However, the remaining rats that avoided on shock trials rarely or never left the drinking chamber within $15 \mathrm{sec}$ on safe trials. These data demonstrate that discriminated avoidance was learned. Table 1 also displays the mean duration of drinking for each animal during the first $15 \mathrm{sec}$ of trials in the final block.

Finally, recall that the lick-noncontingent tone group was included to permit an evaluation of the effect of the lick contingency on tone-cued avoidance. A 3 (groups) $\times 4$ (blocks) ANOVA revealed neither a significant difference between the groups $[F(2,12)$ $=.035]$ nor a significant group $\times$ block interaction $[F(6,33)=.17]$, although the blocks (learning) effect was present $[F(3,33)=3.65, p<.05]$.

\section{DISCUSSION}

The results confirm the finding of Hankins, Rusiniak, and Garcia (1976) in demonstrating that rats can use flavor as a shock-avoidance cue, and extend their finding by demonstrating that they do so as readily as with an auditory cue. In fact, although we do not consider the finding of primary importance, the data reported here suggest that the flavor used
$(.15 \mathrm{M} \mathrm{NaCl})$ served as a better cue than did the $2,900-\mathrm{Hz}$ tone. These data seem to contradict numerous earlier reports which argue that rats are unable (or unlikely) to associate flavor with peripheral pain (shock).

The procedure employed in the present study differed in two important ways from the procedure employed in studies that failed to obtain flavor-cued avoidance. First, we used a more traditional avoidance paradigm in which the animal could obtain the cue and completely avoid the impending shock. Second, flight, rather than suppression of ingestion, was chosen as the avoidance response. This permitted the rat to avoid trauma in an "ethologically" sensible way.

It is not clear whether the outcome was due to the use of an avoidance paradigm, the choice of a locomotor response, or both. But it is clear that the rats learned the relationship between flavor and footshock and between flight and shock avoidance. On the other hand, we saw no evidence of the development of an aversion to the flavor that predicted shock. While ingestion of the shock flavor declined as the rats learned to leave the compartment within $15 \mathrm{sec}$, they continued to drink longer than required to obtain a flavor cue and showed no evidence of disgust or the "hedonic shift" (Garcia, Hankins, \& Rusiniak, 1974) associated with poison-aversion formation. This lack of aversion learning should not be surprising. In both the experimental environment and the rat's historical environment, ingestion (or the lack of it) consistently affects things like stomach distention, blood sugar level, hunger, thirst, and "malaise," but bears no consistent relationship to tactile, thermal, kinesthetic, or nociceptive sensations in the feet. On the other hand, locomotor activity and pedal contact with the environment consistently affect foot sensations, but have no direct effect on stomach distention, blood sugar level, etc. Thus, we should no more expect a rat to avert to the flavor of a substance that predicts footshock than to flee in terror from the sight of a moldy food pellet.

Viewing the matter in this way serves to remind us of the extent to which paradigm choice may constrain one's conclusions. Presumably, if a traditional avoidance paradigm and a locomotor response had been chosen by Garcia and Koelling in 1966, the notion of cue-modality specificity in shock-avoidance learning would have been dismissed.

\section{REFERENCES}

Bothes, R. C. Species-specific defense reactions and avoidance learning. Psychological Review, 1970, 77, 32-48.

Breland, K., \& Breland, M. Animal behavior. New York: Macmillan, 1966.

Domjan, M., \& Wilson, N. E. Specificity of cue to consequence in aversion learning in the rat. Psychonomic Science, 1972, 26, $143-145$.

Garcia, J., Ervin, F. R., \& Koelling, R. A. Learning with 
prolonged delay of reinforcement. Psychonomic Science, 1966, 5, 121-122.

Garcia, J., Hankins, W. G., \& Coil, J. D. Koalas, men, and other conditioned gastronomes. In N. W. Milgram, L. Krames, \& T. M. Alloway (Eds.), Food aversion learning. New York: Plenum Press, 1977.

Garcia, J., Hankins, W. G., \& Rusiniak, K. W. Behavioral regulation of the milieu interne in man and rat. Science, 1974, 185, 824-831.

Garcia, J., \& Koelling, R. A. Relation of cue to consequence in avoidance learning. Psychonomic Science, 1966, 4, 123-124.

Garcia, J., Kovner, R., \& Green, K. F. Cue properties vs palatability of flavors in avoidance learning. Psychonomic Science, 1970, 20, 313-314.

Garcia, J., McGowan, B. K., \& Green, K. F. Biological constraints on learning. In A. Black \& W. F. Prokasy (Eds.), Classical conditioning II. New York: Appleton-Century-Crofts, 1972.

Gellerman, L. W. Chance orders of aiternating stimuli in visual discrimination experiments. Journal of Genetic Psychology, 1933, 42, 207-208.

Green, L., Bouzas, A., \& Rachlin, H. Test of an electric-shock analog to illness-induced aversion. Behavioral Biology, 1972, 7, 513-518.
Green, K. F., Holmstrom, L. S., \& Wollman, M. A. Relation of cue to consequence in rats: Effect of recuperation from illness. Behavioral Biology, 1974, 10, 491-503.

Hankins, W. G., Rusiniak, K. W., \& Garcia, J. Dissociation of odor and taste in shock avoidance learning. Behavioral Biology, 1976, 18, 345-358.

Krane, R. V., \& Wagner, A. R. Taste aversion learning with a delayed shock US: Implications for the generality of the laws of learning. Journal of Comparative and Physiological Psychology, 1975, 88, 882-889.

Miller, S., \& Ericson, R. The odor of taste solutions. Physiology \& Behavior, 1966, 1, 145-146.

Rozin, P., \& Kalat, J. W. Specific hungers and poison avoidance as adaptive specializations of learning. Psychological Review, $1971,78,459-485$.

Seligman, M. E. P. On the generality of the laws of learning. Psychological Review, 1970, 77, 406-418.

(Manuscript received September 10, 1980; revision accepted for publication April 16, 1981.) 